\title{
ENVIRONMENTAL MONITORING OF DRINKING WATER QUALITY OF BIRSK CENTRAL WATER SUPPLY
}

(C) 2017

Islamova Aysylu Ayratovna, candidate of biological sciences, associate professor of Biology and Ecology Department

Kolbina Maria Yuryevna, master student of Biology and Ecology Department

Safikhanov Rishat Yakhievich, candidate of biological sciences, associate professor, director of the College Birsk Branch of Bashkir State University (Birsk, Republic of Bashkortostan, Russian Federation)

Abstract. This paper examines effects of drinking water components, namely calcium and magnesium ions on the human body as well as it lists the main diseases that occur with prolonged use of hard water. Kostarevsky water intake is described as the only source of centralized water supply of the city. The paper contains data of ecological monitoring of drinking water taken from Kostarevsky water intake in Birsk from 2015 to 2017. The authors compare drinking water in Birsk and some other cities of the Republic of Bashkortostan. The chemical composition of the water was determined by titrimetric, gravimetric, colorimetric, organoleptic, and microbiological methods of investigation. The results of the analysis show that the water given to the population of Birsk along the central water supply line is microbiologically favorable. The chemical composition of water almost in all respects meets the requirements of Sanitary Regulations and Standards 2.1.4.1074-01 «Drinking water. Hygienic requirements for water quality». However, the analysis results show that the rigidity of the water exchange is beyond the permissible limit of the norm, which can adversely affect the health of the population. The results obtained during the work can be useful for further ecological monitoring of drinking water in Birsk, Republic of Bashkortostan.

Keywords: drinking water; hardness of water; calcium ions; magnesium ions; influence on human body; excess of macroelements; lack of macroelements; water supply; Birsk; Republic of Bashkortostan; Kostarevsky water intake; chemical analysis of water; ecological monitoring; drinking water monitoring.

УДК 504.06

\section{АНАЛИЗ ВОЗДЕЙСТВИЯ ООО «РЖЕВКИРПИЧ» НА ОКРУЖАЮЩУЮ СРЕДУ И ЭКОЛОГИЧЕСКИЙ МЕНЕДЖМЕНТ ТЕРРИТОРИИ}

(C) 2017

Мягкова Кристина Геннадьевна, студент факультета естественных и инженерных наук Савватеева Ольга Александровна, кандидат биологических наук,

доцент кафедры экологии и наук о Земле, и.о. декана факультета естественных и инженерных наук

Государственный университет «Дубна» (2. Дубна, Московская область, Российская Федерация)

Аннотащия. Резкое усиление техногенного воздействия на окружающую природную среду создало реальную угрозу экологического кризиса. Огромное разнообразие использования природных ресурсов в хозяйственной деятельности человека обусловили необходимость применения системного подхода к анализу природопользования, таким образом, стали формироваться основы системы экологического управления - экологического менеджмента.

В данной статье рассматривается воздействие Ржевского кирпичного завода на такие компоненты окружающей среды, как атмосферный воздух, гидросфера, почвенный покров и литосфера. В настоящее время производство кирпича является одной из ведущих отраслей промышленности строительных материалов, составляя более $50 \%$ общего объема производства стеновых материалов. С точки зрения воздействия на окружающую среду загрязнение происходит на всех этапах производства: подготовка сырья (дробление, помол, просеивание и т.д.), смешивание исходных компонентов в однородную сырьевую хорошо формируемую смесь (приготовление пресс-порошка с использование выгорающих и отощающих добавок, увлажнение, нагревание, перемешивание), производство изделий различными способами уплотнения (прессование).

По результатам анализа предложен комплекс мероприятий с целью минимизации негативного воздействия на окружающую среду и здоровье персонала и населения прилегающей к заводу территории. Поскольку кирпичные заводы достаточно широко распространены по территории Российской Федерации, нередко расположены в городской черте, рынок производства кирпича развивается, тема исследования является весьма актуальной и значимой с практической точки зрения.

Ключевые слова: оценка воздействия; кирпичный завод; технология производства кирпича; окружающая среда; экологический менеджмент; экологические риски; атмосферный воздух; почвенный покров; водные ресурсы; здоровье человека; производственные отходы; минимизация негативного воздействия; меры борьбы.

\section{Актуальность и задачи исследования}

Кирпич является самым древним строительным материалом. Более чем тысячелетняя практика применения кирпича позволяет однозначно отнести его к категории наиболее долговечных строительных материалов. Производство кирпича в России считается крупным производственным процессом, строитель- ный кирпич изготавливается фактически во всех субъектах Российской Федерации. Большинство специализированных кирпичных предприятий являются предприятиями малой мощности, используют местное сырье и, как правило, имеют в распоряжении основной рынок сбыта своей продукции в непосредственной близости от производства. Классическим 
Мягкова К.Г., Савватеева О.А.

примером такого объекта является Ржевский кирпичный завод (ООО «Ржевкирпич»), которому посвящена данная статья.

Цель исследования состоит в анализе воздействия ООО «Ржевкирпич» на окружающую среду и здоровье населения. Так как кирпичные заводы распространены на всей территории Российской Федерации, весьма часто расположены в городской черте, рынок производства кирпича развивается особенно в связи с ростом индивидуального строительства, тематика является весьма актуальной.

Задачами исследования являются следующие:

- изучение ООО «Ржевкирпич» и используемой технологии производства керамического кирпича;
- оценка воздействия ООО «Ржевкирпич» на атмосферный воздух, водную среду, литосферу;

- оценка экологических рисков ООО «Ржевкирпич» для здоровья населения;

- разработка предложений по экологическому менеджменту на предприятии.

\section{Объект исследования}

Кирпичный завод располагается в Тверской области в г. Ржев (рис. 1). Завод расположен на северозападе г. Ржева в 5 километрах от федеральной трассы Москва - Рига (М9), имеет удобные автомобильные и железнодорожные подъездные пути, примыкающие к станции Ржев-Белорусский.

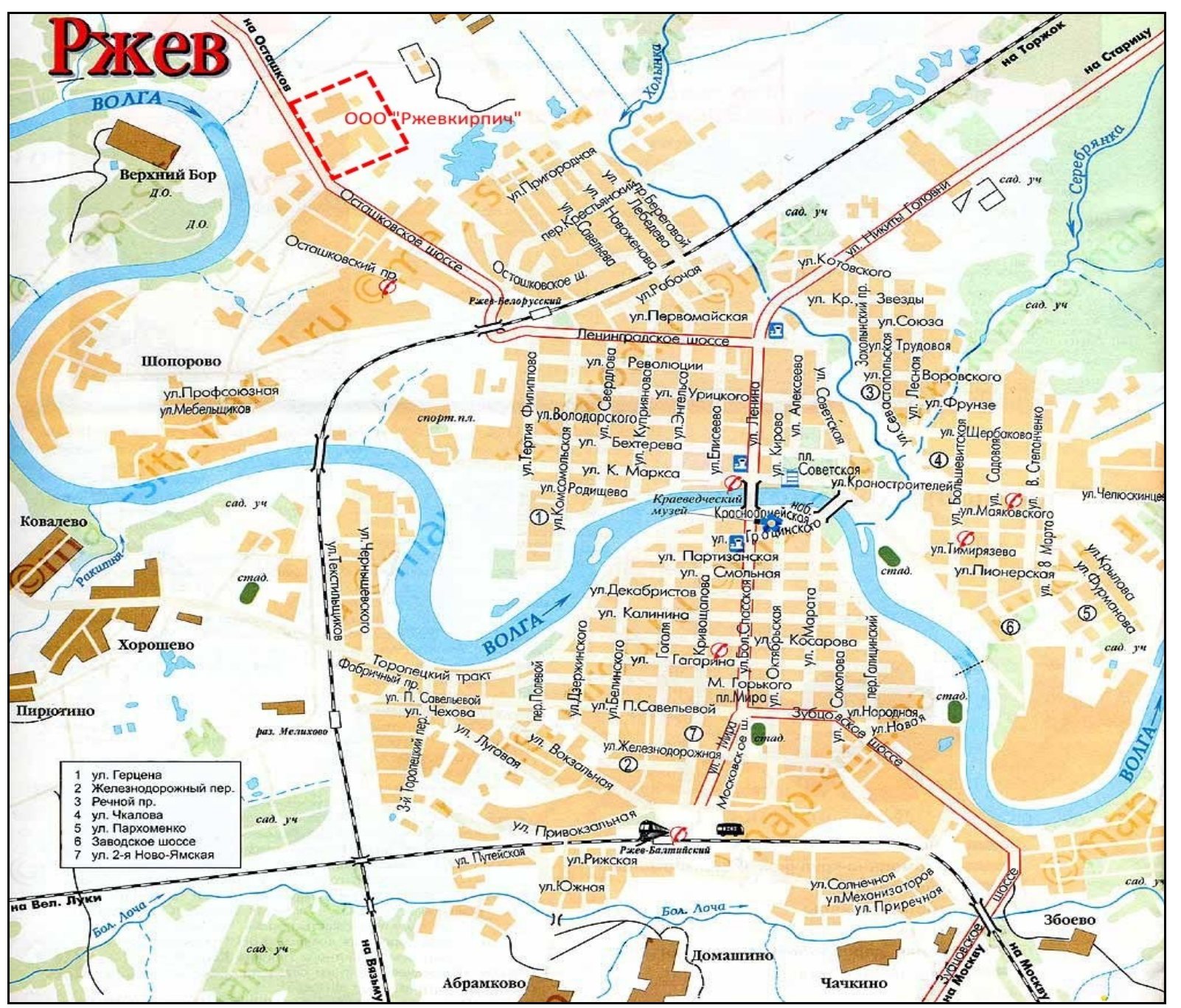

Рисунок 1 - Карта-схема района размещения промышленной площадки № 1000 «Ржевкирпич»

ООО «Ржевкирпич» более 160 лет (с 1850 года) занимается производством строительного керамического полнотелого кирпича марок М100, M125, М150 ГОСТ 530. Основной вид деятельности предприятия - производство керамического строительного кирпича, изготовление блочно-модульных конструкций и разработка карьеров. Объем выпускаемой продукции (по плану) - 28000 тыс. штук. В 2002 году завод вышел на проектную мощность и выпускает около 30 млн. штук кирпича в год [1].

Данный кирпич пользуется устойчивым спросом и поставляется во многие регионы РФ, одним из основных потребителей кирпича является г. Москва.

С 2007 года на заводе освоено производство модульных конструкций для быстрого возведения ма- лоэтажных зданий жилищного, социально-бытового, торгового и промышленного назначения, отвечающих всем мировым стандартам [2].

Предприятие располагается на двух промышленных площадках. На первой промышленной площадке располагаются цеха по производству кирпича, склады и административные здания. На второй промышленной площадке - карьер по добыче глины, зданий и сооружений на площадке нет.

Расстояние до ближайшей жилой застройки составляет 68 м по южному направлению от промплощадки № 1 предприятия. В 2006 году было получено санитарно-эпидемиологическое заключение, удостоверяющее, что ООО «Ржевкирпич» соответствует государственным санитарно-эпидемиологическим 
правилам и нормам. По степени воздействия на окружающую природную среду предприятие относится к 3-й категории опасности. Согласно проекту сокращение санитарно-защитной зоны (С33) произведено до жилой застройки. По остальным направлениям размер С33 остается неизменным, т.е. равным $300 \mathrm{M}$.

Промплощадка № 2 располагается в 12 км северовосточнее города Ржев и в 400 м западнее д. Новое Гузынино. Зданий, строений, сооружений на земельном участке не имеется. Ориентировочный размер С33 составляет 100 м. Ближайший жилой дом от границы территории промышленной площадки № 2 расположен на расстоянии 620 м в д. Новое ГузыниHO.

Зон отдыха и других территорий с повышенными требованиями к охране атмосферного воздуха в пределах влияния выбросов промышленных площадок нет [3].

\section{Методы исследования}

При выполнении работы по оценке воздействия ООО «Ржевкирпич» на окружающую среду были проанализированы проект нормативов предельно допустимых выбросов в атмосферу ООО «Ржевкирпич», проект нормативов образования отходов и лимитов на их размещение ООО «Ржевкирпич», проведены натурные исследования состояния промышленной площадки предприятия. На основе Руководства по оценке риска для здоровья населения при воздействии химических веществ, загрязняющих окружающую среду. Р2.1.10.1920-04, утвержденного Главным государственно-санитарным врачом РФ 05.03.04, выявлены системы органов человека, являющиеся критическими при постоянном хроническом воздействии приоритетных компонентов в составе выбросов предприятия в атмосферный воздух. Также проанализирована эффективность системы обращения с отходами предприятия. Итогом работы являются предложения по минимизации экологических рисков и внедрению системы экологического менеджмента на территории ООО «Ржевкирпич».

Технология производства строительного кирпича

Сырьем для производства кирпича служит глина Новогузынинского месторождения. Глину на месторождении добывают из целика и транспортируют для вылеживания и усреднения в конуса. В качестве сырьевых источников для изготовления кирпича применяют легкоплавкие глины и суглинки $[4 ; 5 ; 6]$. В качестве отощителей применяют кварцевый песок, дегидратированную глину и бой изделий. Содержание отощающих компонентов находится в пределах 20-30\% по массе. Резка кирпича производится с помощью автомата. Далее производится сушка кирпича в противоточных туннельных сушилах. Срок сушки 50-72 часов [4].

Для обжига готовых кирпичей используется природный газ, период обжига составляет 40-48 часов, при температуре $970 \pm 20^{\circ} \mathrm{C}$. После обжига кирпичу доставляют на склад готовой продукции.

Данная технология производства керамического кирпича позволяет получить хороший внешний вид кирпича и высокие эксплуатационные качества [3].
Материалы исследования и их обсуждение

Выбросы в атмосферу происходят в процессе обжига кирпича в специальных печах. Выбросы происходят по причине сгорания топлива для получения тепла, необходимого для обжига, и от влияния высоких температур на саму глину. Выбросы пыли также возникают в результате открытой карьерной добычи глины.

Общий объем выбросов в атмосферу от предприятия составляет 79,226 т/год - около 7\% от валового объема выбросов стационарных источников загрязнения в г. Ржев. Наибольшие объемы выбросов приходятся на такие загрязняющие вещества, как оксид углерода (около 41\%), оксиды азота (34\%), диоксид серы (10\%), взвешенные вещества (7\%), неорганическая пыль: 70-20\% $\mathrm{SiO}_{2}$ (4\%), ксилол (2\%), уайтспирит (2\%). Другие компоненты имеют менее $2 \%$ вклада в общий объем выбросов [7, с. 36].

На первой промышленной площадке имеет 51 источник выбросов: 21 организованный (все источники оборудованы пылеулавливающими агрегатами) и 30 неорганизованных, на второй промышленной площадке - неорганизованный источник выбросов. Все источники организованных выбросов предприятия оборудованы пылеулавливающими агрегатами, с эффективностью очистки 93-95\%, однако воздействие полностью не нейтрализовано [3, с. 27].

Спектр выбрасываемых веществ от предприятия представлен 38 компонентами, среди них к 1 классу опасности относятся бенз(а)пирен и хром шестивалентный; ко 2 классу - сажа, оксиды азота и углерода, марганец и его соединения, серная кислота, сероводород, фтористые газообразные соединения, бензол; к 3 классу - диоксиды азота и серы, вольфрамовый ангидрид, ксилол, толуол, взвешенные вещества, керосин, неорганическая пыль; к 4 классу - углерод, этанол, бензин и другие. Наибольшие объемы выбросов приходятся на такие загрязняющие вещества, как оксид углерода (около 40\%), оксиды азота (35\%), диоксид серы (10\%), взвешенные вещества (7\%), неорганическая пыль: 70-20\% $\mathrm{SiO}_{2}$ (5\%) (рис. 2).

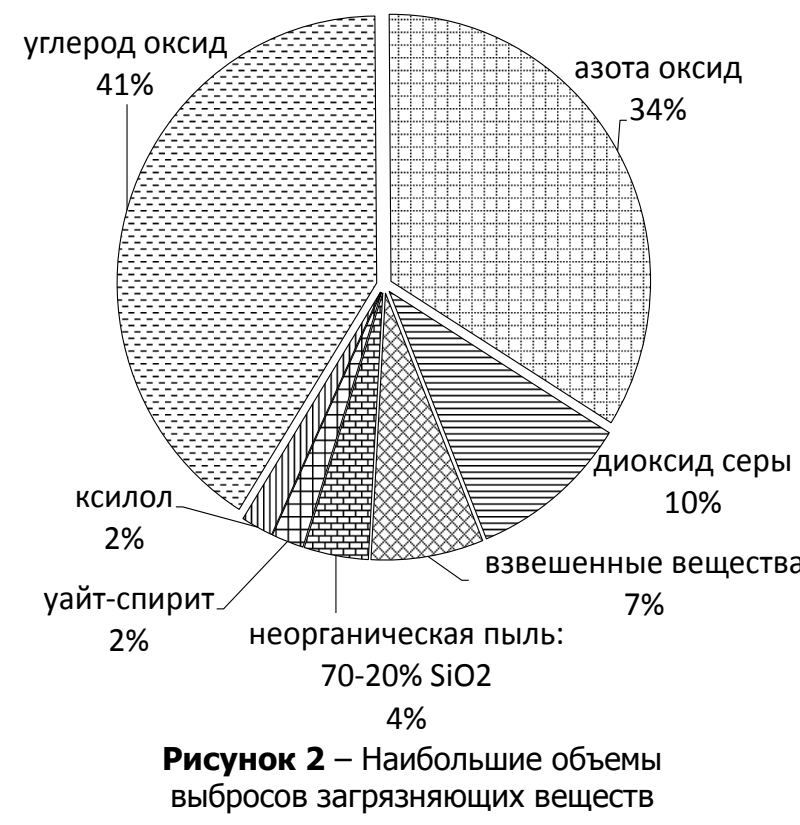


Исходя из состава выбросов загрязняющих веществ ООО «Ржевкирпич», в котором преобладают оксиды углерода, оксиды серы и взвешенные вещества, можно сделать вывод о наличии экологических рисков для здоровья человека, высокой вероятности повышения заболеваемости по ряду нозологий. Так, оксид углерода при хроническом ингаляционном воздействии оказывает влияние на кровеносную систему, центральную нервную систему, возможны заболевания сердечно-сосудистого характера. Оксиды азота в основном влияют на органы дыхания и кровообращения. Диоксиды серы и взвешенные вещества также повышают вероятность возникновения заболеваний органов дыхания, в отдельных случаях могут вызывать смерть. Неорганическая пыль с 70$20 \% \mathrm{SiO}_{2}$ может вызвать заболевания иммунной системы. Ксилол и уайт-спирит воздействуют на центральную нервную систему, органы дыхания, почки и печень [8;9].

Следует также отметить, что в составе выбросов присутствуют соединения фтора, обладающие эффектом вредного действия даже при невысоких концентрациях. Среди выбросов различных пылей Всемирной организацией здравоохранения частицы размером менее 10 мкм - также присутствующие в составе выбросов ООО «Ржевкирпич» - отнесены к приоритетным компонентам по уровню влияния на здоровье населения, их воздействие требует детального изучения $[3$, с. 8$]$.

Кроме того, указанные в составе выбросов данного предприятия загрязняющие вещества могут оказывать неблагоприятное действие на растительность прилегающей территории: оксиды серы и азота разрушают хлорофилл растений, повреждают листовые пластины, неорганическая пыль ухудшает условия дыхания, замедляет рост и развитие растений и т.д.

С точки зрения воздействия на водную среду производственная территория завода находится вне водоохранных зон водных объектов и охранных зон ценных природных комплексов. Ближайший водный объект (р. Волга) расположен на расстоянии $400 \mathrm{~m}$ (рис. 1). Таким образом, непосредственное воздействие на водные объекты предприятие не оказывает, однако карьер по добыче глин для кирпичного производства является, по существу, постоянным источником загрязнения подземных и поверхностных вод. Отвалы вскрышных пород размываются дождевыми и талыми водами, могут разноситься ветром большие расстояния [10].

Относительно воздействия ООО «Ржевкирпич» на почвенный покров и литосферу следует отметить, что в первую очередь влияние оказывает карьер по добыче производственного сырья. Основными видами воздействия в этом направлении являются изъятие земельных ресурсов и изменение рельефа территории в пределах разработки карьера.

Кроме этого, на предприятии организовано 28 площадок временного (до 6 месяцев) складирования отходов, образуется 48 видов отходов 1-5 класса опасности общим объемом 9517,75 т/год. Кроме того, ООО «Ржевкирпич» осуществляет сбор 2475 т/год отходов от сторонних организаций (опилки древесной натуральной чистой древесины, отрабо- танные масла), 5042,34 т/год используют на предприятии, 0,414 т/год обезвреживают (отработанная аккумуляторная серная кислота).

К отходам 1 класса опасности относятся ртутные лампы и отработанный ртутьсодержащие трубки; 2 класса опасности - кислота аккумуляторная серная; 3 класса опасности - лом меди несортированный, пыль цементная, масла автомобильные отработанные, шлам очистки трубопроводов, фильтровочные и поглотительные отработанные массы, текстиль загрязненный, свинцовые аккумуляторы; 4 класса опасности - обтирочный материал, загрязненный маслом, шлак сварочный, покрышки отработанные, абразивная пыль, отходы затвердевшего поливинилхлорида и пенопласта, опилки древесные, загрязненные минеральными маслами, отходы лакокрасочных средств, мусор от бытовых помещений, пыль кирпичная; 5 класса опасности - бой строительного кирпича, отходы сложных полиэфиров, отходы цемента в кусковой форме, абразивные круги отработанные, отходы гипса в кусковой форме.

Максимум объема отходов на предприятии приходится на бой строительного кирпича (4900 т/год $52 \%)$, несортированные древесные отходы (299 т/год - 4\%) и лом черных металлов $(228,42$ т/год - 3\%), отработанные резиновые покрышки (10 т/год) (рис. 3) [11, с. 4].

бой строительного кирпича

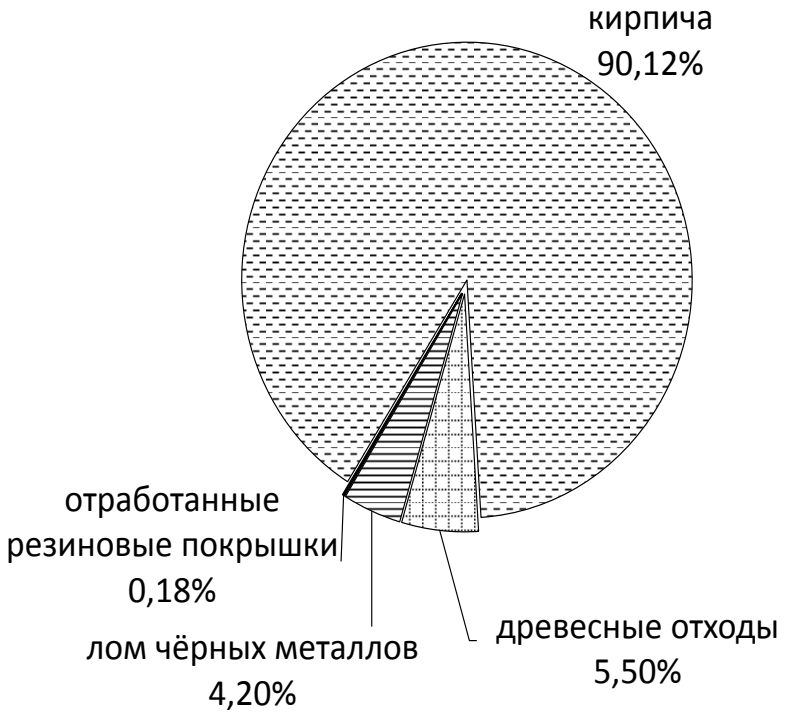

Рисунок 3 - Соотношение преобладающих видов отходов

Кроме того, завод осуществляет сбор опилок натуральной чистой древесины и отработанных масел от сторонних организаций. Некоторые виды отходов предприятие вывозит на полигон ТБО с их последующим захоронением. Также ООО «Ржевкирпич» повторно использует некоторые виды отходов в собственном производственном процессе: бой строительного кирпича, пыль кирпичную, отработанные автомобильные масла и опилки натуральной чистой древесины. Частично опилки древесины передаются населению.

\section{Выводы и предложения}

Предприятие ООО «Ржевкирпич» наибольшее неблагоприятное воздействие оказывает на атмо- 
сферный воздух, что вызывает необходимость повышения эффективности очистки пылеулавливающих агрегатов. На сегодняшний день существует множество установок с высокой степенью очистки, например, «ПОТОК - ВЦП $2.5-10000 »$ имеет эффективность очистки 99,9\%, что, безусловно, снизит негативное воздействие на окружающую среду [12].

На предприятии ООО «Ржевкирпич» необходимо введение комплексной системы экологического менеджмента. Система экологического менеджмента предприятия или организации - часть системы общего менеджмента, которая включает в себя организационную структуру, планирование, распределение ответственности, практические методы, процедуры, процессы и ресурсы, необходимые для разработки, внедрения, реализации, анализа и поддержания экологической политики. Основными инструментами этой системы являются оценка воздействия на окружающую среду, экологический аудит и контроль, экологический мониторинг, в последние годы сюда добавляется рискология [13].

Рассмотрим основные аспекты минимизации негативного воздействия ООО «Ржевкирпич» на окружающую среду и здоровье населения, руководствуясь подходами управления экологическими рисками. Среди методов управления рисками обычно выделяют превентивные, репрессивные, коррекцию последствий негативных событий и компенсационные решения [14-17].

Среди превентивных методов для ООО «Ржевкирпич» можно предложить установку автоматических датчиков по содержанию ТМ 10 и ТМ 2,5 или усовершенствование технологии изготовления керамического кирпича. Также следует обратить внимание на соединения фтора, обладающие эффектом вредного действия, в этом направлении следует провести детальные исследования.

В плане репрессивных методов рекомендуется проведение экологического аудита - проверки и оценки состояния деятельности руководства предприятия по обеспечению рационального природопользования и охраны окружающей среды от негативных воздействий, ее соответствия требованиям законодательства Российской Федерации, которые проводятся для выявления прошлых и существующих экологически значимых проблем, подготовки рекомендаций по совершенствованию деятельности.

Среди мер борьбы с последствиями негативных событий для данного предприятия наиболее эффективной можно считать рекультивацию территории карьера, где уже закончена добыча сырья, например, одним из самых распространенных способов рекультивации отработанных глиняных карьеров является использование их под полигоны ТБО (полигоны твердых бытовых отходов). Остаточные слои глины выполняют функции дополнительного экрана, увеличивая эффективность предотвращения загрязнения почвы как на самом полигоне ТБО, так и вне полигона [18].

В качестве компенсационных методов по управлению риском можно предложить введение системы экологического страхования, а также запрос государственной помощи, например, для модернизации или замены пылеулавливающего оборудования с большими показателями улавливания.
На многих предприятиях существует социальное страхование от несчастных случаев на производстве и профессиональных заболеваний. Предприятие обязуется возмещать вред, причиненный жизни и здоровью при исполнении обязанностей по трудовому договору [19; 20].

Также можно предложить организацию медикоэкологического мониторинга персонала предприятия c последующей диспансеризацией и санаторнокурортным лечением при выявлении профессиональных заболеваний.

\section{СПИСОК ЛИТЕРАТУРЫ:}

1. Историческая справка [Электронный ресурс] // ООО «Ржевкирпич» - http://kirpich.rzhevonline.ru/ ?pg=002.

2. Экономика и промышленность Ржева [Электронный ресурс] // Городской интернет портал Ржев. -http://rzev.ru/modules/myfiles/myfile04.php.

3. Проект нормативов предельно допустимых выбросов в атмосферу. ООО «Ржевкирпич». Тверь, 2013.

4. Подготовка сырья для производства кирпича [Электронный pecypc] // http://vsyglina.org.ru/index.php/ 2012-03-25-05-43-54.

5. Поскрёбышев В.А. Механическое оборудование для производства строительных материалов и изделий. Братск: ГОУ ВПО «БрГУ», 2009. 378 с.

6. Кашкаев И.С., Шейнман Е.Ш. Производство глиняного кирпича. М.: Высшая школа, 1978. 248 с.

7. Государственный доклад о состоянии и об охране окружающей среды в Тверской области в 2013 году [Электронный ресурс] // http:/greentver. ucoz.ru/load/gosudarstvennyj_doklad/1-1-0-4.

8. Макар С.В. Основы экономики природопользования. М.: Институт международного права и экономики им. А.С. Грибоедова, 1998. 192 с.

9. Агапов Н.Н., Шевчук А.В. Экономика природопользования и охраны окружающей среды. М.: Классика-плюс, 1999. 287 с.

10. Геоэкологические исследования [Электронный ресурс] // Электронная библиотечная система. http://elib.altstu.ru/elib/books/Files/va2000_1/pages/17 p/17.htm.

11. Проект нормативов образования отходов и лимитов на их размещение. ООО «Ржевкирпич». Тверь, 2014.

12. Пылеулавливающий агрегат модели «ПОТОКВЦП 2.5-10000» [Электронный ресурс] // Техприбор. -http://tpribor.ru/potokvcp.html.

13. Свиткин М.3., Мацута В.Д., Рахлин К.М. Системы экологического менеджмента: методика и практика применения. СПб.: СПб. картфабрики ВСЕГЕИ, 2002. 243 с.

14. Самойлова Н.А. Экологический менеджмент. Кемерово: Кемеровский технологический институт пищевой промышленности, 2014. 184 с.

15. Трифонова Т.А., Селиванова Н.В., Ильина М.Е. Экологический менеджмент. Владимир: Владим. гос. ун-т, 2003. 291 с.

16. Пахомова Н., Рихтер К., Эндрес А. Экологический менеджмент. Практикум. СПб.: Питер, 2004. $352 \mathrm{c}$.

17. Белов Г.В. Экологический менеджмент предприятия. М.: Логос, 2006. 240 с. 
18. Руководство по оценке риска для здоровья населения при воздействии химических веществ, загрязняющих окружающую среду. Р 2.1.10.1920-04. Утв. Гл. гос.-сан. врачом РФ 05.03.04.

19. Макаров С.В., Иванова Т.А., Александрова Е.В. Оценка эффективности деятельности предприятий в области экологического управления и менеджмента // Экология и промышленность России. 1998. № 10. $42 \mathrm{c}$.

20. Дайман С.Ю. Системы экологического менеджмента для практиков. М.: РХТУ им. Д.И. Менделеева, 2004. 248 с.

\section{LLC «RZHEVKIRPICH» IMPACT ON THE ENVIRONMENT AND ENVIRONMENTAL MANAGEMENT OF THE TERRITORY}

(C) 2017

Myagkova Christina Gennadievna, student of Natural and Engineering Sciences Faculty

Savvateeva Olga Alexandrovna, candidate of biological sciences, associate professor, associate professor of Ecology and Earth Sciences Department, head of Natural and Engineering Sciences Faculty Dubna State University (Dubna, Moscow Region, Russian Federation)

Abstract. A sharp increase of anthropogenic impact on the environment has created a real threat to the ecological crisis. A huge variety of natural resources use in human activities led to the use of a systematic approach to the environmental management analysis, as well as to environmental management. This paper considers Rzhev brick factory impact on such environmental components as air, hydrosphere, soil and lithosphere. Currently, the production of bricks is one of the leading sectors of the building materials industry, accounting for more than $50 \%$ of the total production of wall materials. From the environmental point of pollution occurs at all stages of production: raw materials preparation (crushing, grinding, sifting, etc.), mixing of starting components into a homogeneous good shape commodity (preparation of press-powder with the use of emaciated and burnable additives, hydration, heating and mixing) and production with the help of various methods of pressing. As a result of the analysis the authors suggest a complex of measures to minimize negative impacts on the environment and health of workers and the public. As brick plants are widely distributed on the territory of the Russian Federation and as they are quite often located in urban areas, the market for brick production develops, the authors think that the subject is very relevant and important from a practical point of view.

Keywords: impact assessment; brick plant; technology of brick production; environment; environmental management; environmental risks; atmospheric air; soils; water resources; human health; waste production; minimization of negative impacts; control measures.

УДК 581.9

\section{ХАРАКТЕРИСТИКА РАСТИТЕЛЬНОСТИ УНИКАЛЬНОГО УЧАСТКА САМАРСКОЙ ОБЛАСТИ «ГУБИНСКО-ТРОЕКУРОВСКИЕ ВЫСОТЫ»}

(C) 2017

Новикова Любовь Александровна, доктор биологических наук, доцент,
профессор кафедры общей биологии и биохимии
Пензенский государственный университет (2. Пенза, Российская Федерация)

Саксонов Сергей Владимирович, доктор биологических наук, профессор, заместитель директора по научной работе, заведующий лабораторией проблем фиторазнообразия

Васюков Владимир Михайлович, кандидат биологических наук, научный сотрудник лаборатории проблем фиторазнообразия

Горлов Сергей Евгеньевич, аспирант лаборатории проблем фиторазнообразия

Сенатор Степан Александрович, кандидат биологических наук, старший научный сотрудник лаборатории проблем фиторазнообразия

Институт экологии Волжского бассейна РАН (2. Тольятти, Самарская область, Российская Федерация)

Соловьева Вера Валентиновна, доктор биологических наук,

профессор кафедры биологии, экологии и методики обучения

Самарский государственный сочиально-педагогический университет (2. Самара, Российская Федераџия)

\footnotetext{
Аннотация. Во флоре Губинско-Троекуровских высот (Самарская область), расположенных в пределах Средне-Волжского биосферного резервата, выявлено 467 видов сосудистых растений, из них 26 раритетных видов: Adonanthe vernalis, Astragalus zingeri, Bupleurum falcatum, Catabrosella humilis, Clausia aprica, Cotoneaster laxiflorus, Crataegus volgensis, Ephedra distachya, Ferula caspica, Fritillaria ruthenica, Galatella angustissima, Gentiana cruciata, Hedysarum grandifolium, Iris aphylla, Iris pseudacorus, Iris pumila, Jurinea ledebourii, Jurinea multiflora, Koeleria sclerophylla, Linum perenne, Polygala sibirica, Pulsatilla patens, Scabiosa isetensis, Stipa korshinskyi, Stipa pennata, Thymus zheguliensis. На более выровненных участках развиваются дерновиннозлаковые настоящие степи с доминированием Stipa capillata и Cleistogenes squarrosa. На пологих склонах (угол наклона менее $30^{\circ}$ ) формируются также дерновиннозлаковые настоящие степи с доминированием Stipa pennata, Stipa lessingiana и Helictotrichon desertorum. На крутых склонах (угол наклона более $30^{\circ}$ ) развиваются кальцефитные бобовые настоящие степи с доминированием Astragalus tenuifolius, разнотравные настоящие степи (Potentilla glaucescens, Centaurea carbonata) и полукустарничковые настоящие степи
} 